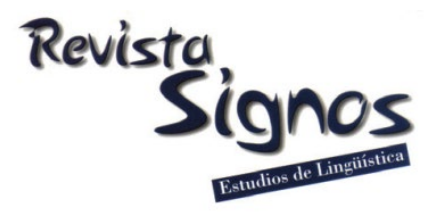

\title{
La recategorización léxica. Nombres colectivos y nombres recategorizados como colectivos ${ }^{1}$
}

\author{
Lexical recategorization. Collective nouns and nouns \\ recategorized as collective
}

\author{
Elena de Miguel \\ UNIVERSIDAD AUTÓNOMA DE MADRID \\ ESPAÑA \\ elena.demiguel@uam.es
}

Recibido: 16-IX-2018 / Aceptado: 28-XI-2018

DOI: $10.4067 /$ S0718-09342019000200531

\section{Resumen}

Este trabajo se ocupa de la recategorización léxica que experimentan algunos nombres individuales cuando se interpretan como colectivos en determinados contextos; el proceso se vincula a la existencia de un rasgo sub-léxico en la definición del nombre individual, potencialmente capacitado para ser coaccionado y desencadenar un cambio de tipo semántico en el nombre. El artículo defiende, pues, una definición flexible y permeable para las unidades léxicas y para las clases en que se agrupan en función de su significado, y una concepción del cambio regular y productiva, ligada al contexto, y restringida por la propia potencialidad de la palabra. La hipótesis se inserta en el modelo del Lexicón Generativo (Pustejovsky \& Batiukova, 2018), según el cual la entrada de las palabras en el lexicón mental es un conjunto infraespecificado de rasgos o fragmentos de contenido, distribuidos de forma jerárquica y muy estructurada, y capacitados para especificarse en los distintos contextos. El modelo presupone además la existencia de un conjunto de mecanismos generativos, entre ellos, el de coacción, al que aquí se atribuye la recategorización léxica de los nombres individuales como colectivos. El análisis sub-léxico propuesto vincula el cambio de categoría léxica al contexto en que se produce la coacción de un rasgo; por tanto, prevé que, fuera de ese contexto, la palabra pertenece a la clase a la que originariamente está adscrita; el comportamiento gramatical de los nombres individuales objeto de este estudio confirma la propuesta.

Palabras Clave: Coacción, Lexicón Generativo, nombre individual, nombre colectivo, rasgo sub-léxico. 


\begin{abstract}
This study deals with the process of lexical recategorization that some individual nouns undergo when interpreted as collective in certain contexts. This process is linked to the presence of a sub-lexical feature in the definition of individual nouns, which can be coerced and trigger a change in their semantic typing. Thus, this paper advocates a flexible and permeable definition of lexical items and semantic classes of lexical items, and a regular and productive conception of lexical change, which is determined by the context and constrained by the potential of the word itself. This hypothesis is framed within the Generative Lexicon model (Pustejovsky \& Batiukova, 2018), where the entries in the mental lexicon are underspecified sets of semantic features or fragments structured hierarchically and potentially able to become specified in different contexts. In addition, this model assumes the existence of a set of generative mechanisms. One of them is coercion, which is made responsible for recategorizing individual nouns as collective in this study. In the sublexical analysis here expounded, the change of lexical category is related to the context wherein coercion takes place. Therefore, it is assumed that, outside this context, the word belongs to its original class. The grammatical behavior of the individual nouns confirms this hypothesis.
\end{abstract}

Key Words: Coercion, Generative Lexicon, individual noun, collective noun, sublexical feature.

\title{
INTRODUCCIÓN
}

El presente trabajo se ocupa de la recategorización léxica, proceso por el cual una palabra cambia de clase léxica en un determinado contexto. Por ejemplo, el nombre no contable 'algodón' ('aquí apenas se cultiva algodón’) se recategoriza léxicamente como contable cuando coaparece con un cuantificador (como 'tres' en 'usó tres algodones para desmaquillarse cada ojo'). El fenómeno ha recibido diversos nombres: entre ellos, 'modificación del tipo denotado por la palabra' (Bosque, 2000), 'reclasificación' y ‘traslación' (Bosque, 2016) y los más extendidos 'coacción' y ‘coerción': estos últimos son traducciones del término coertion, usado en el modelo del Lexicón Generativo (LG, a partir de ahora; Pustejovsky, 1995; Pustejovsky \& Batiukova, 2018) para aludir al mecanismo de generación de significado que cambia el tipo léxico-semántico de una palabra en un determinado contexto (ver apartado 3.3.).

Las recategorizaciones léxicas son muy frecuentes: los nombres no solo pasan de no contables a contables ('algodón' $>$ 'tres algodones'), sino también de contables a no contables ('tener un coche' $>$ 'tener coche'), de concretos a abstractos ('hacerse un blanqueamiento dental' $>$ 'castigar el blanqueamiento del dinero negro'), de abstractos a concretos ('sentir amor' $>$ 'ser su primer amor'), de denotar un evento a referirse a un objeto ('la entrada es a las diez' $>$ 'he revendido mi entrada') y viceversa ('le han regalado una bicicleta muy aerodinámica' > 'le han prohibido la bicicleta, por ser perjudicial para su rodilla'). Ahora bien, según se defiende aquí, no es lo mismo ser miembro estable de una clase léxica que adscribirse a ella transitoriamente, en calidad de 'invitado contextual', afirmación que implica varios supuestos: (i) que existen clases 
de palabras: p.ej., la de los nombres contables y la de los no contables; (ii) que el contexto puede hacer que una palabra de una clase léxica pase a comportarse como miembro de otra: p.ej., el cuantificador en 'usó tres algodones'; y (iii) que el comportamiento de los miembros de una clase léxica es diferente del de las palabras recategorizadas contextualmente.

El objeto de este artículo es, precisamente, probar el acierto del tercer supuesto: el diseño del lexicón mental resulta más sistemático y predecible, y su estudio más abordable, si los mecanismos que operan en él lo hacen en condiciones restringidas y solo permiten cambios de clase léxica transitorios; si se presupusiera que las unidades léxicas experimentan cambios de clase irrestrictos y con carácter definitivo, tanto la definición de la unidad como el propio concepto de clase se verían seriamente amenazados.

Este trabajo defiende la hipótesis de que los cambios de clase léxica de una palabra son transitorios y vienen determinados por la materialización, en los distintos contextos, de significados potencialmente contenidos en su definición. Esta hipótesis, inserta en el marco teórico del LG, se apoya en el presupuesto básico de la 'infraespecificación' de las entradas léxicas en el lexicón mental (ver apartado 3.). De acuerdo con este supuesto, las definiciones infraespecificadas de las palabras se especifican en distintos sentidos en función del contexto. En los contextos seleccionados automáticamente, se especifican en un sentido esperado, 'literal' o 'canónico'; en los contextos no seleccionados de manera automática, se especifican en un sentido menos esperado, aparentemente 'figurado', 'metonímico' o 'metafórico'. Unos y otros sentidos se generan a través de mecanismos igualmente regulares y productivos. La diferencia estriba en el tipo de mecanismo que opera en cada caso: los significados aparentemente 'literales' resultan de la operación de un mecanismo de selección, mientras que los significados aparentemente 'no literales' se obtienen a través de un mecanismo de coacción ejercido por el contexto.

La palabra coaccionada, que adquiere o pierde rasgos que la definen, puede experimentar un cambio de clase léxica. Ahora bien, el cambio es transitorio, puesto que está vinculado a un determinado contexto; por eso, al someter la palabra a las pruebas que discriminan su clase léxica, la recategorización solo se manifiesta en el contexto que la desencadena. Fuera de él, el comportamiento de la palabra sigue siendo el de los miembros de la clase a la que pertenece originariamente en virtud de su significado 'literal'. Ello avala la propuesta de que las entradas léxicas constan de unos rasgos básicos de significado, independientes del contexto; las clases léxicas se establecen en función de esos rasgos mínimos.

La cuestión de la recategorizacion léxica plantea interesantes retos a las distintas explicaciones sobre la relación entre el léxico y la sintaxis. En principio, el hecho de que una palabra de una clase se comporte como miembro de otra en función de los 
requisitos de las palabras que la acompañan, habla a favor de una explicación de naturaleza construccionista: para este tipo de enfoque, la interpretación de una palabra (y su consiguiente adscripción a una clase léxica) deriva del contexto en que entra (p.ej., 'algodón' como nombre contable cuando va acompañado del cuantificador 'tres'). Un análisis en estos términos resulta económico puesto que evita postular múltiples sentidos para las palabras. Sin embargo, algunos hechos sugieren que la construcción no es libre ni autosuficiente para recategorizar las palabras:

(i) no cualquier palabra de una misma clase léxica admite reinterpretarse en un mismo contexto. Por ejemplo, el nombre no contable 'solidaridad', a diferencia de 'algodón', no se recategoriza como contable en compañía del cuantificador: *'tres solidaridades';

(ii) las palabras no admiten cualquier reinterpretación. Por ejemplo, 'plato', en cuanto que nombre de [objeto] ('un plato de porcelana') de tipo [contenedor] ('un plato sopero'), legitima una interpretación metonímica de [contenido] ('he comido \{un plato muy sabroso'/'el plato del día\}'). Ahora bien, la recategorización de los nombres de contenedor como nombres de contenido, aunque muy frecuente, no es irrestricta: 'plato' puede ser complemento de 'comer' pero no de 'beber', verbo que selecciona complementos con el rasgo léxico [contenido [líquido]]; la definición de 'plato' carece del rasgo [líquido] o de otro que permita recategorizarlo en ese sentido;

(iii) el que dos palabras muy próximas en su definición se comporten de manera diferente respecto de la recategorización avala también la propuesta de que esta deriva de la información potencial contenida en la entrada léxica. Acabamos de ver que el rasgo [contenedor] del nombre 'plato' legitima su reinterpretación como [contenido] en los contextos he comido \{un plato muy sabroso/el plato del día\}'. En cambio, el mismo rasgo del nombre 'fuente' no desencadena la misma distribución contextual: *'he comido \{una fuente muy sabrosa/la fuente del día\}'. La definición de 'fuente' incluye información sobre las dimensiones del objeto referido y sobre su uso habitual: se trata de un [contenedor] en el que cabe más cantidad de comida que en un plato y se destina a contener comida para más de un comensal. Por tanto, aunque 'plato' y 'fuente' comparten fragmentos de significado y, en concreto, ambos son nombres de [contenedor], el rasgo [para distribuir] impide que 'fuente' sea complemento de 'comer', excepto en un sentido hiperbólico: 'me he comido una fuente de chuletas yo solito’.

El hecho de que el contexto no sea suficiente ni libre para recategorizar una palabra si esta no incluye en su definición algún rasgo que favorezca la recategorización parece avalar, pues, un análisis de corte determinista, según el cual es el contenido sub-léxico de la palabra el que determina que entre o no en cierto contexto. No obstante, este tipo de explicación se enfrenta también a un problema: prácticamente todas las palabras pueden reinterpretarse como miembros de distinta clase léxica en función del contexto; una postura extrema podría llegar a postular que no existen significados fijos ni clases de palabras estables (De Miguel, 2009) 
En realidad, el problema que supone para un análisis léxico-sintáctico la frecuencia con que las palabras cambian de clase se puede evitar si se asume, como hacemos aquí, que las unidades del léxico son entidades poco especificadas, muy flexibles y permeables al contexto, y que las clases léxicas en las que se agrupan son también muy poco rígidas y están por ello abiertas a la incorporación constante de miembros no permanentes, los 'invitados contextuales'. Desde esta perspectiva, el rasgo sub-léxico se define por su potencialidad para ser especificado, y el contexto por su capacidad para especificarlo, en una interesante integración de supuestos construccionistas y proyeccionistas que ya se ha usado para explicar las frecuentes recategorizaciones o coacciones aspectuales de los verbos (De Miguel, 2015), y que permite superar algunos de los inconvenientes que los cambios de clase léxica ligados al contexto plantean a los análisis habituales.

En suma, la propuesta de este trabajo defiende la existencia de: (a) un significado mínimo en las palabras que justifica el establecimiento de las clases léxicas; (b) unos mecanismos de generación de significado, vinculados al contexto, que coaccionan las palabras y permiten reinterpretarlas en distintos sentidos; (c) un comportamiento gramatical diferenciado para los miembros estables de una clase léxica y para las palabras que se adscriben transitoriamente a una clase en función del significado desencadenado por coacción. Esta propuesta se ilustra con un caso particular de recategorización o coacción: la de ciertos nombres individuales de entidad o institución (como 'banco', 'colegio' o 'periódico'), y otros como 'ciudad', 'pueblo' o 'trabajo,' que se interpretan esporádicamente como colectivos, en ciertos contextos coactivos; fuera de ellos, se comportan como individuales, lo que avala la hipótesis de que los cambios de clase léxica vinculados al contexto no son estables ni tienen repercusión gramatical.

El trabajo se organiza como sigue: la sección 1 contiene una breve reflexión sobre el concepto de clase léxica en la investigación lingüística actual, una vez 'dinamitada' y 'dinamizada' la concepción tradicional; en la sección 2. se incluye la hipótesis y en el apartado 3. se recogen algunos presupuestos del modelo del LG, en el que se inserta la hipótesis: en concreto, se describe el mecanismo de la coacción, al que se atribuye la recategorización léxica objeto de nuestro estudio. En la sección 4. se presentan las propiedades de los nombres colectivos y se da cuenta de la reinterpretación como colectivos de algunos nombres individuales en ciertos contextos. El artículo se cierra con las conclusiones y la bibliografía. 


\section{Las clases de palabras. Breve reflexión sobre el concepto de clase léxica}

\subsection{La dinamitación del concepto tradicional de clase de palabras}

Durante el largo periodo que conocemos con el nombre de Gramática Tradicional, la discriminación de las clases de palabras constituyó un asunto recurrente, que giraba en torno a criterios nocionales del tipo 'un verbo es la palabra que expresa una acción' o 'un adjetivo es la palabra que expresa cualidad', hoy descartados: no todos los verbos expresan acciones ni solo los verbos expresan acciones, no todos los adjetivos expresan cualidad ni solo los adjetivos expresan cualidad (Bosque, 1989). Por otra parte, un criterio nocional no permite distinguir las 'categorías funcionales' (conjunción, determinante, pronombre), que carecen de significado.

En efecto, las palabras no se organizan en categorías gramaticales en función de su significado: pueden tener muchos, compartirlos con miembros de otras categorías e incluso no tener: un nombre es nombre con independencia de que se refiera a un objeto ('algodón') o denote un evento ('blanqueamiento'); cuando denota un evento comparte el significado con los verbos; y cuando es un nombre ligero ('situación' en 'estar en una situación crítica'), apenas significa. Ahora bien, las unidades léxicas que forman parte de una misma categoría gramatical, sí se distribuyen en distintas clases por lo que significan: de ahí que se distingan verbos de estado y de acción, adjetivos de cualidad y de relación, y nombres de objeto y de evento, cuyo diferente comportamiento sintáctico y morfológico deriva precisamente de su diferente contenido. En consecuencia, del comportamiento gramatical de una palabra se deduce la clase léxica a que pertenece.

La lingüística actual asume la existencia de un vínculo estable entre el significado de una palabra, al que se accede a través de su comportamiento gramatical, y su adscripción a una clase. Las clases léxicas se establecen, pues, a partir de criterios gramaticales y no meramente nocionales (Bosque, 2016). Ello supone la ruptura de las fronteras entre las clases de palabras tradicionales y la reagrupación de sus miembros en nuevas clases léxicas, establecidas en virtud de un comportamiento gramatical vinculado a algún rasgo de contenido léxico; por tanto, sus miembros pueden pertenecer a distintas categorías gramaticales: así, el rasgo [evento] integra toda palabra que denote un evento (verbo, nombre o preposición) en la clase de las palabras eventivas; la especificación del rasgo [ $₫$ homogéneo] reúne nombres no contables y verbos atélicos por un lado, y nombres contables y verbos télicos por otro (De Miguel, 2016); en las clases de 'predicados de individuo' y 'predicados de estadio' se incluyen adjetivos y verbos (Marín, 2004); la clase de los 'predicados psicológicos' agrupa nombres, verbos y adjetivos (Marín, 2015). Y también forman una clase transcategorial las 'palabras ligeras', a la que se adscriben verbos, nombres y adjetivos 
que, por su escaso contenido, resultan "transparentes" a efectos de la selección contextual (De Miguel, 2011; Bosque, 2016).

\subsection{La dinamización del concepto de clase léxica}

El nuevo concepto de clase léxica, dinámico y flexible, gira en torno a la identificación de rasgos de contenido en palabras, de idéntica o distinta categoría gramatical, que comparten comportamientos sintácticos o morfológicos. Y, lo que es más interesante, permite la entrada y salida esporádica de los miembros, cuando el contexto los incita a comportarse como miembros de otra clase: p.ej., los nombres no contables que se vuelven contables ('algodón' $>$ 'tres algodones') o los nombres de evento que se recategorizan como objeto ('la entrada es a las diez' > 'he revendido mi entrada'). Este nuevo enfoque permite visualizar una red de relaciones entre palabras de distintas categorías gramaticales, por un lado, palabras de distintas clases léxicas, por otro, y contextos en los que las palabras pueden coaparecer, de manera automática o tras una negociación del significado, en sintonía con las tendencias actuales en la investigación lingüística, que pivotan en buena medida sobre el concepto de red: el diccionario combinatorio REDES (Bosque, 2004) certifica ese nuevo interés, en la medida en que no proporciona definiciones de las palabras, sino una imagen del mapa de sus redes en el lexicón mental.

En este momento son muchos los proyectos interesados por las relaciones que mantienen las palabras como parte de una red que las distribuye en grupos en función de ciertos rasgos o fragmentos de significado (De Miguel, 2014). Los nuevos enfoques, centrados en redes de palabras con rasgos internos idénticos o compatibles que cruzan categorías, dibujan un panorama flexible, interconectado y dinámico. Sobre los rasgos que definen las palabras, y sancionan su pertenencia a una clase, operan mecanismos de selección y coacción, que legitiman o descartan sus combinaciones. La investigación actual en léxico-sintaxis tiene entre sus objetivos centrales el de individuar los rasgos que permiten a las palabras formar clases y redes, y el de identificar los mecanismos de concordancia de rasgos que dan cuenta de las relaciones que mantienen (De Miguel, 2016). Para ello se hace preciso investigar en el interior de la palabra, dentro de su definición, en lo que antes llamábamos entrañas y hoy ADN, en consonancia con la llamada 'revolución genetista', que facilita un nuevo modo de estudiar el léxico.

En efecto, muchas de las modernas teorías en semántica léxica se interesan por la búsqueda del elemento más pequeño de significado: el rasgo sub-léxico o fragmento básico de significado. De igual modo que para la fonología de comienzos del siglo xx supuso un salto teórico fundamental el paso del fonema al rasgo distintivo, la propuesta de rasgos sub-léxicos (subeventos, fases, factores o fragmentos) abre un mundo nuevo de redes, relaciones, conexiones y materializaciones. La unidad de estudio del léxico deja de ser una entidad atómica y se concibe como una entidad 
compleja y articulada, permeable a las influencias de otras y flexible para experimentar cambios en sus componentes. Esta concepción se ajusta bien a la concepción dinámica del lexicón mental, como módulo donde tienen lugar las conexiones entre los rasgos de las entradas léxicas. La transmisión de información léxica a través de vínculos, nodos y redes puede concebirse en términos muy próximos a lo que se llama la 'sinapsis': es decir, la generación de significados debe ser resultado de un proceso de transmisión de información regular y no ad hoc.

A la espera de lo que digan en el futuro la genética, la biología molecular o la neurociencia, de momento consideramos la palabra como un 'saco' poroso y permeable al contexto, con un conjunto de rasgos subléxicos en su interior; algunos de ellos son prominentes y fácilmente accesibles, otros son secundarios y están opacos pero pueden visualizarse y volverse definitorios, cuando se combinan con los rasgos subléxicos de otras palabras. El contexto materializa, pues, sentidos potencialmente contenidos en la estructura interna de una palabra. En función de los rasgos subléxicos que comparten (plena o parcialmente), las palabras de distintas clases establecen redes que explican sus compatibilidades contextuales y justifican las coacciones o recategorizaciones léxicas.

\subsection{Los rasgos subléxicos en una definición articulada y dinámica de la palabra}

Los rasgos sub-léxicos son fragmentos de información que componen el significado de las palabras y que tienen relevancia gramatical; por tanto, para identificarlos observamos el comportamiento sintáctico de las palabras. La naturaleza de los rasgos subléxicos es estrictamente lingüística, en varios sentidos:

(a) aunque a menudo se aprecie un vínculo entre el rasgo propuesto para una palabra y las propiedades de la entidad en el mundo a la que esta alude, el vínculo no tiene por qué existir; por eso las lenguas pueden codificar de forma distinta una misma entidad en el mundo. Así, 'línea' y 'raya' aluden en español al mismo objeto que linea y riga en italiano, pero su comportamiento sintáctico indica que su definición es distinta: 'línea' y 'raya' se definen como [figura geométrica] y 'línea', además, como [contenedor]. Ese rasgo legitima una lectura de [contenido] para 'línea', que justifica el contraste 'leer unas \{líneas/*rayas\}'. Por su parte, linea y riga son [figura geométrica] pero es riga el nombre que se define como [contenedor] y admite la lectura metonímica de [contenido], según ilustra leggere alcune $\{$ righe/*linee\}. La diferente distribución del rasgo [contenedor] explica también por qué el evento de trazar una figura geométrica bajo una palabra en español se llama 'subrayar' y en italiano sottolineare.

(b) aunque en ocasiones no es fácil identificar las propiedades de una entidad en el mundo, los rasgos subléxicos de la palabra que la designa pueden establecerse de forma independiente, porque su asignación se basa en criterios de naturaleza gramatical; es decir, el comportamiento 
sintáctico y morfológico de una palabra permite individuar sus rasgos subléxicos: así, la compatibilidad con el predicado 'lleno' indica que el nombre 'línea' tiene el rasgo [+contenedor] y 'raya' no: 'la \{línea / *raya está llena'.

(c) los rasgos propuestos, por su naturaleza estrictamente lingüística, pueden cruzar categorías de palabras que denotan entidades de distinta naturaleza ontológica, lo que confirma que la clasificación léxica es independiente del mundo: así, el nombre 'algodón' y el verbo 'andar' comparten el rasgo [+homogéneo] y, por eso, son compatibles con el cuantificador 'mucho' ('mucho algodón'; 'andar mucho'), aunque aluden a entidades ontológicamente distintas: el nombre a un objeto y el verbo a un evento. Los rasgos subléxicos cruzan no solo las clases léxicas sino también las categorías gramaticales: los rasgos [ \pm homogéneo], [ \pm evento],

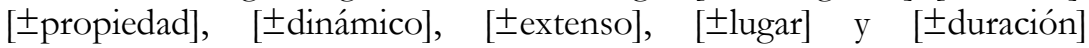
discriminan nombres, verbos, adverbios, adjetivos y preposiciones. En suma, permiten establecer paradigmas léxicos cuyos miembros comparten su comportamiento gramatical, sin atender al tipo de entidades del mundo a las que aluden -a diferencia de los rasgos que conforman los campos léxicos de la lexemática estructural y de los primitivos semánticos de la lingüística cognitiva (De Miguel, 2016) -.

La nómina de rasgos subléxicos que conforman el significado de las palabras no ha sido establecida de forma definitiva, pero no debe estar abierta ni ser muy amplia. Es su combinación lo que determina la gama, muy extensa pero no infinita, de significados posibles. Por lo que respecta a los nombres, la clasificación que aquí se asume se organiza en torno a los rasgos [objeto] [evento] y [propiedad] (en línea con Pustejovsky, 1995). Esta primera taxonomía distingue los nombres no eventivos, los eventivos y los abstractos de cualidad, grosso modo. Estas clases se dividen a su vez, en función de otros rasgos, siempre productivos y con repercusión gramatical, entre ellos, [ \pm artificial], [ \pm estructura interna], [ \pm homogéneo], [ \pm delimitado] y [ \pm dinámico], y otros, ya de carácter menos general, que discriminan solo algunas clases léxicas, como [ \pm lugar $],[ \pm$ instrumento], [ \pm contenedor], [ \pm contenido], [ \pm información], [ \pm institución] y [ \pm animado], que distinguen clases de nombres de objeto. Los rasgos se solapan y entrecruzan, y generan un conjunto muy amplio de tipos léxicos (Romero, 2017 para una propuesta de clasificación de nombres por sus rasgos sub-léxicos.)

\section{La recategorización como un cambio de rasgos sub- léxicos}

La hipótesis de este trabajo defiende que la recategorización léxica constituye una modificación, transitoria y vinculada al contexto, de la definición de una palabra en términos de sus rasgos sub-léxicos. La modificación consiste en la introducción o supresión de un rasgo o, más apropiadamente, en el cambio de especificación de un rasgo en la palabra recategorizada, y está motivada por los requisitos de selección de las palabras con las que se combina. Se trata de un proceso regular, productivo y 
restringido: exige, además de ciertas condiciones contextuales, que la palabra que cambia de clase léxica contenga en su definición un rasgo sub-léxico que propicie el cambio.

En la medida en que el cambio de categoría léxica de la palabra recategorizada se vincula a un contexto, no es definitivo, a diferencia de lo que ocurre con las palabras que adquieren un nuevo significado con independencia del contexto (como 'ratón' 'mamífero roedor' > 'aparato informático'). La recategorización léxica es un cambio transitorio, y así lo prueba el comportamiento gramatical de la palabra recategorizada

La hipótesis se inscribe en el modelo del LG, cuyos presupuestos asume: (a) las unidades léxicas están dotadas de un contenido infraespecificado, que se especifica en los diferentes contextos en diferentes sentidos; (b) ese contenido se codifica en rasgos subléxicos de distinta naturaleza, distribuidos en diversos niveles de una metaentrada muy jerarquizada y estructurada; y (c) existen unos mecanismos de generación de significado que operan sobre las informaciones de las definiciones infraespecificadas de las palabras.

\section{La organización del léxico según el modelo del Lexicón Generativo}

El modelo del LG (Pustejovsky, 1995; Pustejovsky \& Batiukova 2018) constituye una teoría formal sobre la organización y estructura del léxico cuyo objetivo fundamental es dar cuenta de la 'polisemia sistemática', fenómeno regular y supuestamente universal, por el cual las palabras son capaces de adquirir múltiples significados dependiendo del contexto en que aparecen. Así lo ilustra el adjetivo 'ligera' que, en función del nombre al que acompaña, significa 'poco voluminosa' (1a)-, 'que se digiere bien' -(1b) - y 'que no exige por parte del espectador un esfuerzo de reflexión’-(1c)-(De Miguel, 2009):

(1) a. Una maleta ligera

b. Una comida ligera

c. Una comedia ligera

d. \# Una laguna ligera

La explicación del LG se asienta en dos presupuestos básicos: el de que las entradas léxicas están infraespecificadas y el de que el contexto las especifica.

De acuerdo con el primer supuesto, la definición infraespecificada de una palabra subsume los múltiples sentidos que puede adquirir en el contexto, cuando las palabras con las que se combina materializan alguna de sus potencialidades semánticas; la información potencial no siempre es transparente pero sí es permeable a las informaciones de otras palabras: así, en (1a), 'ligera' combinada con 'maleta', que se 
define como objeto [contenedor], predica su peso (y, por metonimia, también el de su [contenido]).

De acuerdo con el segundo presupuesto, el significado se construye en el contexto, pero no de manera libre e irrestricta, sino por una motivación léxica: 'ligera' no se combina con 'laguna', que carece de un rasgo [contenedor] -el símbolo \# en (1d) indica que solo se acepta como una vulneración propia del lenguaje poético-. En cambio, sí se predica de 'comida' y de 'comedia', aunque carecen del rasgo [contenedor]. La aceptabilidad de (1b-c) se atribuye a la intervención de un mecanismo de rescate que coacciona el significado de las palabras para formar expresiones interpretables. Entre los objetivos fundamentales del modelo está, precisamente, el de identificar los mecanismos, hipotéticamente regulares y universales, que posibilitan que una forma léxica infraespecificada adquiera una interpretación única y determinada en la composición de la oración (revisar apartado 3.3.).

\subsection{La definición de la palabra como meta-entrada infraespecificada $y$ estructurada}

Para el LG, las informaciones potenciales de la definición infraespecificada de una palabra se distribuyen de forma jerarquizada en una meta-entrada muy estructurada, que consta de diversos niveles de representación o subestructuras: la Estructura Argumental (que codifica la información sobre los argumentos que selecciona una palabra predicativa), la Estructura Eventiva (que codifica la información sobre el tipo de evento que denota un predicado) y, fundamentalmente, la Estructura de Qualia (EQ), que codifica en cuatro dimensiones semánticas ciertos contenidos básicos de la entidad aludida por una palabra: el 'quale formal' (QF, información sobre el tipo de entidad que es y cómo se relaciona con otras de su mismo dominio), el 'quale constitutivo' (QC, información sobre su constitución interna), el ‘quale agentivo' (QA, información sobre cómo llega a existir) y el 'quale télico' (QT, información sobre su destino u objetivo).

La información codificada en la EQ ha sido a menudo considerada enciclopédica pero no lo es: corresponde a la palabra y da cuenta de su comportamiento combinatorio. En (2) se proporciona la EQ del nombre 'conductor' y en (3) se ofrecen ejemplos que ilustran cómo los modificadores adjetivos y preposicionales materializan los diferentes parámetros de la EQ del nombre. (A este respecto, De Miguel (2009); De Miguel \& Batiukova (2017), de donde proceden los ejemplos (2-6) con alguna variación.) 
(2) conductor

EQ $\left(\begin{array}{l}\text { QF: individuo animado } \\ \text { QC: atributos relevantes (físicos y de otro tipo) } \\ \text { QA: preparación teórica y práctica /obtención de permiso } \\ \text { QT: conducir un automóvil }\end{array}\right)$

(3) a. un conductor \{alto / simpático / británico $\}$ QQF]

b. un conductor con \{mala visión nocturna / problemas de lateralidad / piernas demasiado largas $\}$ [QC]

c. un conductor \{veterano / inexperto / autorizado / sin carnet [QA]

d. un conductor \{torpe / rápido / brusco [QT]

\subsection{Tipos de nombres en función de los valores de la EQ}

En función de los valores recogidos en su EQ, los nombres se agrupan en tres tipos: 'naturales' ('simples'), 'unificados' ('artefactuales' o 'funcionales') y 'complejos'.

Los nombres de tipo natural se refieren a entidades que existen de manera natural; solo incluyen valores para el QF y el QC. P.ej., 'caballo', 'roca' o 'agua', que se definen en función del tipo de entidad que son: por su constitución externa $(\mathrm{QF})$ e interna (QC).

Los nombres de tipo unificado o funcional se refieren a artefactos, entidades creadas artificialmente con un fin: p.ej., 'biberón', 'cuchillo' o 'profesor', objetos físicos y además instrumentos que sirven a una determinada función (beber, cortar, enseñar). Su definición tiene más dimensiones que la de los tipos naturales, ya que incluye información relativa al proceso de su creación (QA) y el objetivo al que se destinan (QT). Por eso en ocasiones resultan polisémicos: 'la abuela dio el biberón al niño' (= 'la abuela entregó un objeto al niño'/'la abuela hizo que el niño bebiera el líquido contenido en un recipiente').

Los tipos complejos (también llamados dot objects), se componen de dos o más tipos en su EQ: constituyen un producto cartesiano $(\mathrm{x}, \mathrm{y})$ entre los tipos que los componen. Se representan formalmente con el operador lógico $\operatorname{dot}(\bullet)$, que sirve para construir tipos complejos ('a $a$ b') a partir de dos tipos ('a' y 'b'). Por ejemplo [alimento] y [evento] forman un tipo complejo en 'comida', a partir de dos tipos no necesariamente compatibles.

Cada uno de los tipos que componen un nombre de tipo complejo tiene su propia EQ; por ello, pueden desplegar comportamientos sintácticos e interpretaciones semánticas diferentes, en función de los valores de la EQ que materialice el contexto: 
(4) a. La quinoa es una comida [alimento] vegetal muy sana y nutritiva.

b. La comida ${ }_{[e v e n t o]}$ benéfica contó con muchos asistentes.

Los ejemplos de (4a-b) proyectan de forma disyuntiva los distintos tipos contenidos en el QF. Si se proyectan simultáneamente se produce ambigüedad, hecho muy frecuente; las palabras de tipo complejo son sistemáticamente polisémicas:

(5) a. No me gustó la comida[alimento] $\bullet$ [evento]

b. Ya se ha acabado la comida $[$ alimento $\bullet[$ [evento].

Los tipos complejos admiten co-predicación, fenómeno por el cual dos predicados distintos acceden simultáneamente a dos significados distintos de una palabra:

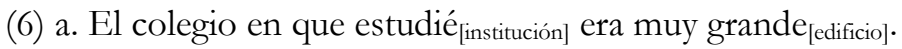

b. La clase de gramática ${ }_{[\text {evento] }}$ era la peor iluminada ${ }_{[\text {recinto] }}$.

\subsection{La coacción del tipo de argumento impuesta por el predicado}

Los ejemplos de (4) ilustran cómo un predicado puede acceder a uno u otro de los tipos que componen un tipo complejo y los de (5) cómo puede acceder conjuntamente a dos tipos simples de los incluidos en uno complejo. Desde la perspectiva aquí asumida, estos casos pueden verse como consecuencia de la operación de procesos de selección entre palabras cuyos rasgos sub-léxicos concuerdan. Ahora bien, en contra de lo que podría esperarse, las palabras no suelen concordar de forma plena, o al menos no en primera instancia; por el contrario, es muy frecuente que los requisitos de selección de las palabras no sean satisfechos por sus argumentos, a pesar de lo cual las combinaciones generadas suelen ser aceptables. Veámoslo con un par de ejemplos:

El verbo 'leer' exige como complementos nombres con el rasgo sub-léxico [información]: p.ej., 'libro', que es un tipo complejo ([objeto físico]•[Información] (según ilustra el contraste 'un libro mal encuadernado' / 'un libro muy didáctico'). Sin embargo, 'leer' se combina a menudo de forma aceptable con nombres que carecen del rasgo [información]: p.ej. 'pizarra', que es un [objeto físico], en 'Alicia leyó la pizarra'. De acuerdo con la propuesta del LG, en estos casos se produce la intervención de un mecanismo de 'coacción' que recategoriza 'pizarra' como tipo complejo: [objeto físico]•[información]. El mecanismo por el cual el nombre pasa de ser simple a complejo se considera regular y productivo, y no es libre, sino que está restringido a la potencialidad de la palabra: la información contenida en el QT de la EQ del nombre 'pizarra', que define el [objeto físico] aludido como un instrumento destinado a escribir información en él, permite su recategorización contextual en el nuevo sentido. 
Otro caso paradigmático del mecanismo de coacción del tipo es el de 'novela', nombre de [objeto] que se reinterpreta como nombre de [evento] cuando se combina con 'empezar'. 'Empezar' selecciona complementos eventivos ('empezó a llover', 'empezó el eclipse') y rechaza, en principio, los que no lo son (*`empecé \{el viento/la luz\}'). Pero con mucha frecuencia el verbo coacciona al nombre para denotar un evento, a fin de satisfacer sus requisitos léxicos, y la combinación se rescata; para que ello ocurra es preciso que el nombre tenga predisposición para ser recategorizado; 'novela' se define como el producto de un evento de creación, el de escribir (información contenida en su QA), y su creación tiene como objetivo un evento, el de ser leída (información contenida en su QT); por eso, aunque es un nombre de objeto, cuando se combina con 'empezar' puede denotar un evento de los contenidos en su EQ: el de escribir o el de ser leída, o ambos. En suma, la coacción no opera libre e indiscriminadamente: las posibilidades de reinterpretación de la palabra coaccionada están previstas en su EQ. De no ser así, se produce un colapso interpretativo, como el que se ilustra en (1d).

El significado obtenido por coacción contextual no se recupera fuera del contexto coactivo: 'novela' no se interpreta como evento en cualquier combinación (p.ej., en \#'envolví la novela para regalo’) y su recategorización léxica no tiene consecuencias gramaticales: no responde a las pruebas que identifican un nombre como eventivo, como la compatibilidad con 'asistir', 'presenciar', 'ocurrir' y 'tener lugar': *‘ $\{$ asistí a/presencié\} la novela'; *'la novela \{ocurrió/tuvo lugar\} ayer'. De hecho, las definiciones de diccionario de 'pizarra' y 'novela' no recogen las lecturas (de información y de evento) ligadas a un contexto, que son regulares, productivas y deducibles.

Las versiones más recientes del modelo distinguen varios tipos de coacción (Pustejovsky, 2011; Pustejovsky \& Ježek, 2008): fundamentalmente, (a) la 'coacción por introducción', cuando el predicado introduce una información en un argumento para volverlo compatible; es el caso de 'leer', que introduce el rasgo [información] en 'pizarra'; y (b), la 'coacción por explotación', cuando el predicado explota o liga un significado de los incluidos en la metaentrada, en detrimento de otros; p.ej., en (4a), donde 'nutritiva' explota [alimento] y en (4b), donde 'benéfica' explota [evento].

En el siguiente apartado vamos a examinar ciertos casos de recategorización de nombres individuales como colectivos, resultado de una coacción vinculada al contexto.

\section{La clase de los nombres colectivos}

En lo que queda de este trabajo se va a analizar el comportamiento gramatical específico de la clase léxica de los nombres colectivos y se van a examinar las condiciones contextuales en que algunos nombres individuales se recategorizan como colectivos. 


\subsection{La definición de nombre colectivo y sus propiedades gramaticales}

Un nombre colectivo es el que designa en singular un referente plural: un conjunto de individuos o entidades que comparten un rasgo definitorio que justifica su agrupación ${ }^{2}$. Son nombres colectivos: 'bibliografía', 'clase' ('conjunto de alumnos'), 'club', 'departamento', 'equipaje', 'ejército', 'familia', 'flota', 'grupo (de whatsapp)', 'muchedumbre', 'obra' ('conjunto de obras'), 'orquesta', 'población', 'público', 'rebaño' y 'tribunal'. El QF de su definición codifica el rasgo [conjunto de miembros], de consecuencias gramaticales. El QC codifica el tipo de miembros que componen el conjunto: naturales ('familia', 'rebaño', 'público') o artificiales ('flota', 'orquesta', 'tribunal'), animados ('ejército', 'familia', 'población', rebaño') o inanimados ('bibliografía', 'equipaje', 'flota', 'obra dramática'), individuales ('familia', 'rebaño') y colectivos ('ejército', 'conjunto de fuerzas aéreas o terrestres de una nación', según lo define el DLE; ‘agrupación', ‘armada', ‘consorcio', ‘corporación’ y ‘federación’’3.

Los colectivos que constituyen tipos naturales no codifican información sobre su creación ni su objetivo, por lo que los adjetivos 'antiguo' (*'un antiguo rebaño') y 'excelente' (*'un rebaño excelente') no pueden modificar información de un QA o un QT respectivamente; en cambio, los colectivos que constituyen tipos funcionales designan entidades creadas con un fin y sí permiten la modificación del QA y del QT ('una antigua flota'; 'una orquesta excelente'; 'un tribunal pésimo').

Algunos nombres colectivos son tipos complejos y codifican en su QF más de un tipo léxico; p.ej., 'club' o 'compañía' se definen como [conjunto de miembros] [entidad]: el club o la compañía pueden existir como sociedad legal con independencia de que no tengan ningún socio. En ese caso, la modificación adjetiva puede explotar uno u otro tipo: en 'un club deportivo', 'deportivo' predica del QT de [entidad]; en 'un club muy deportivo', predica del QC de [conjunto de miembros]. Igualmente, 'ejército' es un nombre de tipo complejo [conjunto de miembros] • [entidad]; el adjetivo 'profesional' en 'un ejército profesional' predica del QA de [entidad] pero en 'ejército muy profesional' modifica al QC del [conjunto de miembros]. 'Departamento' es también un nombre de tipo complejo: el adjetivo 'escindido' modifica al QA de la [entidad] en 'un departamento escindido de otro', y al QC del [conjunto de miembros] en 'un departamento escindido respecto de su apoyo al decano'. Esta posibilidad de tener una lectura de entidad distinta de la del conjunto y constituir, por tanto, nombres de tipo complejo, está vedada a los nombres colectivos de tipo natural, como 'público' o 'rebaño', que carecen de existencia independiente de la de sus miembros.

Al vincular la condición de nombre colectivo a su comportamiento gramatical quedan fuera de la clase ciertos nombres que denotan objetos que se pueden percibir en el mundo como conjuntos de cosas: 'arroz', 'banco' (en el sentido de 'entidad bancaria'), 'ciudad', 'colegio' (en el sentido de 'institución académica'), 'cordillera', 
'gente', 'pinar' o 'pueblo'. ${ }^{4}$ Las pruebas que permiten diagnosticar si un nombre es colectivo son:

(a) La modificación con los adjetivos 'numeroso', o su antónimo 'reducido', a la derecha, que predican el número, amplio o escaso, de miembros que forman parte de un conjunto:

(7) a. Este año tengo clases muy \{numerosas / reducidas\}.

b. Lope de Vega es autor de una obra muy numerosa y Lauro Olmo de una obra reducida.

c. Formo parte de un departamento muy numeroso.

d. Estrenaron ante un público reducido.

En tanto que predicados de pluralidades de individuos, 'numeroso' y 'reducido' no pueden combinarse con los nombres individuales:

(8) a. * Este año tengo un alumno numeroso.

b. * Gutierre de Cetina escribió un madrigal numeroso.

c. * Lo recité ante un espectador reducido.

d. * Lo hice mientras fui una profesora reducida.

La imposibilidad de coaparición con ‘numeroso' y 'reducido' a la derecha identifica como 'falsos colectivos' a nombres como 'arroz', 'pinar' o 'cordillera', que se refieren a entidades que en el mundo pueden percibirse como conjuntos 'de granos', 'de pinos' o 'de montañas', pero no codifican el rasgo sub-léxico [conjunto de miembros] en su QF. Son, pues, nombres individuales: 'arroz' es el nombre no contable de una planta; 'pinar' es el nombre contable de un 'sitio o lugar poblado de pinos' y 'cordillera' es el nombre contable de una 'forma del relieve terrestre constituida por una o varias alineaciones de montañas con una dirección determinada' y, por tanto, no se combinan con 'numeroso' y 'reducido', como se ve en (9a-c). A su vez, la inaceptabilidad de (9d-f) muestra que 'gente', 'pueblo' y 'ciudad' tampoco son nombres colectivos, aunque sus referentes en el mundo sean conjuntos de personas de hecho, el diccionario académico los define como grupos o conjuntos: según el DLE, 'gente' (s.v., $1^{\mathrm{a}}$ acepción) se define como 'pluralidad de personas', 'pueblo' (DLE, s.v., $3^{\mathrm{a}}$ acepción) como 'conjunto de personas de un lugar, región o país' y 'ciudad' (DLE, s.v., $1^{\text {a }}$ acepción) como 'conjunto de edificios y calles...'-. Por su parte, el símbolo de sostenido que precede a 'reducido' en (9e-f) indica que la combinación es posible si el adjetivo predica las dimensiones del referente del nombre $(\approx$ 'de tamaño pequeño'), no de un número de miembros.

(9) a. *He comprado un arroz muy \{numeroso / reducido .

b. ${ }^{*}$ Me gusta pasear por pinares $\{$ numerosos / reducidos\}.

c. ${ }^{*}$ Escalé una cordillera \{numerosa / reducida\}.

d. $*$ Ha acudido al concierto una gente muy $\{$ numerosa / reducida $\}$. 
e. $*$ Pertenezco a un pueblo muy $\{$ numeroso /\# reducido $\}$.

f. * Vivo en una ciudad muy \{numerosa / \# reducida $\}$

(b) En la misma línea, los adjetivos 'grande' y 'pequeño', con los nombres colectivos, predican dimensiones de conjuntos -como en (10a-c)-; en cambio, con los individuales -'clase', nombre de recinto, sinónimo de 'aula', y 'cueva', en (10d-e)- y con los falsos colectivos -los de (10f-h)-, los adjetivos predican dimensiones de individuos:

(10) a. Tengo a mi cargo clases muy grandes y tardo mucho en corregir las prácticas.

b. El pastor cuida un rebaño muy pequeño y tarda poco en recogerlo.

c. Ahora está presentando su trabajo ante un público mucho más grande. (https://www.linguee.es/espanol-

ingles/traduccion/ante + un $+\mathrm{p} \% \mathrm{C} 3 \% \mathrm{BAblico}$.html)

d. Los seminarios del máster se dan en clases muy grandes.

e. Las cuevas de Altamira no son muy grandes.

f. En Altamira no cabe gente grande.

g. No me gusta el arroz tan grande.

h. Vivo en \{un pueblo / una ciudad\} grande.

El hecho de que 'grande' en (10f) no aluda a las dimensiones de un grupo en el mundo sino a las dimensiones de los elementos que lo constituyen (las personas) confirma que 'gente' no codifica en su QF el rasgo [conjunto de miembros] y, por tanto, no se comporta gramaticalmente como un colectivo; lo mismo pasa con 'arroz': 'grande' en (10g) predica el tamaño de los elementos (los granos) que constituyen la entidad referida por 'arroz'. En ambos casos, el adjetivo materializa la información codificada en el QC de 'gente' y 'arroz': un rasgo subléxico [estructura interna [entidades homogéneas]] que legitima la predicación de una propiedad compartida por las entidades homogéneas que constituyen el objeto referido.

Por lo que respecta a 'pueblo' y 'ciudad', son nombres individuales de [lugar [habitado]] y su QF tampoco codifica el rasgo [conjunto de miembros]; por tanto, el adjetivo 'grande', combinado con ellos, predica las dimensiones de un espacio, y no las de un conjunto, según ilustra (10h). El hecho de que, en este caso -a diferencia de lo propuesto para 'gente' y 'arroz' en (10f-g)-, 'grande' no aluda al tamaño de las entidades que conforman un pueblo o una ciudad se debe a que estas son heterogéneas y no admiten la predicación de una propiedad compartida: el rasgo subléxico codificado en el QC de 'pueblo' y 'ciudad' es [estructura interna [entidades heterogéneas]].

c) Una tercera prueba que identifica un nombre como colectivo es que, al contener en su definición el rasgo [conjunto de miembros], admite como complemento un SP que especifique sintácticamente una subclase de los miembros del conjunto. La 
imposibilidad de (11h) confirma que 'gente' no es colectivo: si los hipotéticos miembros de un conjunto en el mundo no se pueden materializar como complemento preposicional del nombre es que el nombre no es colectivo. ${ }^{5}$

(11) a. Un rebaño de ovejas merinas

b. Un ejército de soldados profesionales

c. Una clase de alumnos principiantes

d. Un público de espectadores entendidos

e. Una orquesta de músicos italianos

f. Una muchedumbre de indignados

g. Un banco de peces

h. Ha llegado gente *(de personas, de...)

(d) Otra prueba del carácter colectivo de un nombre es su compatibilidad con los verbos 'ampliar' y 'recortar' en predicados que denoten un aumento o una reducción del número de miembros que integran su referente, como en (12a-b):

(12) a. Este año hemos ampliado \{la familia / el rebaño $\}$.

b. Han recortado \{el ejército / los tribunales de tesis\}.

c. $*$ Han recortado $\{$ (a) la gente / el pueblo / la ciudad $\}$.

d. ${ }^{*}$ Han ampliado $\{$ el arroz / la cordillera $\}$.

e. \#He recortado \{el flequillo / el gasto en gasolina\}.

f. \#Han ampliado \{el pueblo / la ciudad\}.

Con ese sentido, 'recortar' y 'ampliar' no admiten como complemento nombres cuyo QF no contenga el rasgo [conjunto de miembros], p.ej., 'gente', 'pueblo' y 'ciudad' en (12c) o 'arroz' y 'cordillera' en (12d). Sí admiten nombres individuales, pero el predicado denota un aumento o disminución de las dimensiones de un objeto individual, como 'flequillo' o 'gasto' en (12e); asimismo, 'pueblo' y 'ciudad' en (12f), nombres individuales de [lugar [habitado]], admiten la combinación con 'ampliar', pero el resultado expresa que su extensión ha aumentado, no que hayan pasado a tener más habitantes. La ausencia del rasgo [conjunto de miembros] explica también los datos de (13): 'formar' admite como complementos nombres colectivos -(13a-b)-, pero 'arroz' y 'gente' no lo son $-(13 \mathrm{c}-\mathrm{d})-$ :

(13) a. Hemos formado una orquesta para tocar lo que nos gusta.

b. Esperaron a conocerse bien antes de formar una familia.

c. *Hemos formado un arroz.

d. ${ }^{*}$ Hemos formado una gente. ${ }^{6}$

(e) Si un nombre es colectivo se combina con 'abandonar', 'entrar', 'incorporar', 'ingresar', 'salir' y 'sustituir' y el predicado expresa que un individuo pasa a formar parte o deja de formar parte del conjunto al que se refiere el nombre; así es en (14a-f): 
(14) a. Juan abandonó el club por discrepancias con la directiva.

b. Pedro entró en la familia hace muchos años.

c. Incorporé dos ovejas más al rebaño.

d. Juan ingresó en el ejército el año pasado.

e. Pedro se salió de mi grupo de amigos de WhatsApp.

f. Pedro sustituyó a Juan en la orquesta.

g. * Juan entró en la gente hace dos años.

h. * El vecino \{se incorporó al / ingresó en el $\}$ pueblo hace dos años.

i. *Pedro sustituyó a Juan en la gente

j. \# Juan abandonó la cordillera ayer.

k. \# Juan salió del \{pinar/pueblo\} hace un rato.

Los ejemplos (14g-i) son inaceptables porque 'gente' y 'pueblo' no son nombres colectivos. En cuanto a (14j-k), son aceptables pero no con el sentido de 'dejar de formar parte de un colectivo' sino con el de 'dejar de estar en un lugar': el QF de 'cordillera', 'pinar' y 'pueblo' codifica el rasgo [lugar], no el de [conjunto de miembros] $]^{7}$.

e) También prueba el carácter colectivo de un nombre el que concuerde a veces con el verbo en plural -(15a-b)-, o constituya el antecedente de un pronombre plural $-(15 c)-$ :

(15) a. Una bandada de golondrinas emigraron hacia lugares cálidos.

(https://www.fundeu.es/noticia/la-esquina-del-idioma-concordancia-adsensum/)

b. A partir de ahí tienen quince días, la familia, para decidir dónde van a enterrar sus restos. (Noticias Telecinco, 24/08/2018, 21h11m)

c. La comisión jurídica de la Liga Nacional Francesa de fútbol [...] optó por privar al equipo de dicha ciudad [Saint-Ėtienne] de siete puntos, lo que equivale a enviarles de la undécima plaza a una decimosexta. (EL PAÍS, 1701-2001: 43)

Solo los nombres con el rasgo [conjunto de miembros] en su QF legitiman una relación sintáctica con verbos y pronombres en plural ${ }^{8}$. Con independencia de que la concordancia en plural se manifieste preferentemente en ciertas condiciones contextuales, que no se abordan aquí, lo importante es que con los nombres individuales no se da?

(f) Finalmente, la compatibilidad con la preposición 'entre' también permite discriminar los nombres colectivos de los individuales. Los complementos que selecciona 'entre' han de tener como núcleo un nombre homogéneo: esto es, un colectivo, un individual en plural o un no contable. Por tanto, si un nombre contable en singular se combina con 'entre' es porque es colectivo, como los de (16a-e); ${ }^{10}$ un individual es compatible con 'entre' solo si está en plural, según ilustra (16f). El 
contraste entre (16g) y (16h) confirma, pues, que 'pinar' no es un nombre colectivo: solo se combina con 'entre' cuando aparece en plural:

(16) a. Ha localizado a sus abuelos entre el público.

b. Se ha colado una oveja churra entre el rebaño de merinas.

c. Hay mucho descontento entre la orquesta.

d. Le vi perderse entre la muchedumbre.

e. Se han avivado los conflictos entre la familia.

f. Ha aparecido una trufa $\{$ entre los pinos / *entre el pino $\}$.

g. *Ha aparecido una trufa entre el pinar.

h. Qué bonita está la niña [...] entre los pinares verdes

(Camarón de la Isla, Vamos niño pa la bamba (Bambera) por Soleá. https://depaloenpalo.wordpress.com/2013/02/21/camaron-de-la-islaantologia-vol-2-1996/)

\subsection{Los nombres de entidad o institución como falsos colectivos}

Según las pruebas recogidas en la sección 4.1., los nombres 'banco', 'colegio', 'periódico' y 'trabajo' no son colectivos: no aceptan la modificación con 'numeroso' (o 'reducido') a su derecha - $(17 \mathrm{a}-\mathrm{d})$-, no complementan a los verbos 'recortar' o 'formar' -(17e,f) - ni a la preposición 'entre' -(17g-j)- y no desencadenan concordancia en plural $-(17 \mathrm{k})-$.

(17) a. *Trabajo en un banco numeroso.

b. *Fui alumna de un colegio público muy numeroso.

c. ${ }^{*}$ Colaboré con un periódico muy reducido.

d. *Entré como becario en un trabajo reducido.

e. *Un día, sin previo aviso, el Ministerio recortó el colegio.

f. *Los empleados despedidos formaron un \{banco / colegio / periódico / trabajo\}.

g. Encontraron un inspector infiltrado $\{$ en el / dentro del / *entre el $\}$ banco.

h. $\{*$ Entre / En $\}$ el trabajo hay mucho descontento.

i. Hay muchos contratados precarios $\{*$ entre el / dentro del / en el $\}$ periódico

j. *Entre el colegio había muchas maestras republicanas.

k. El \{banco/colegio/periódico\}, de repente, \{decidió / *decidieron\} despedirle.

Los verbos 'recortar' y 'ampliar' los admiten como complemento pero no predican las dimensiones de un colectivo sino las de un objeto -en (18a) se modifica un papel o una entidad, y en (18b) un espacio o recinto, o una entidad- o de un evento -en (18c)-. 
(18) a. Hemos recortado el periódico.

b. Han ampliado el \{banco / colegio\}.

c. Han \{ampliado / recortado $\}$ el trabajo.

Asimismo, los adjetivos 'grande' y 'pequeño', predicados de 'periódico', 'banco' y 'colegio', aluden a las dimensiones de un objeto -un papel, un lugar, un establecimiento, un recinto o una entidad) - y no a las de un conjunto de miembros:

(19) Es un \{periódico / banco / colegio\} muy grande

En suma, 'banco', 'colegio', 'periódico' y 'trabajo' no responden a las pruebas como colectivos: ${ }^{11}$ son nombres individuales. Sin embargo, cuando se combinan con los verbos 'abandonar', 'entrar', 'incorporarse', 'ingresar' y 'salir(se)' reciben una interpretación próxima a la de los colectivos: los ejemplos de (20) se parafrasean como ' $\{$ pasar a formar parte/dejar de formar parte\} del referente del nombre', lectura similar a la que desencadena 'ejército' en (14d):

(20) a. Juan entró en el $\{$ banco/colegio/periódico/trabajo $\}$ por ser hijo de un empleado.

b. Juan se salió del \{banco/colegio/periódico/trabajo\} para volar por su cuenta.

Este comportamiento como 'falsos colectivos' de 'banco', 'colegio', 'periódico' y 'trabajo' refleja que han sufrido una recategorización léxica vinculada al contexto, resultado de la operación del mecanismo generativo de 'coacción del tipo denotado por el nombre', descrito supra en el apartado 3.3. La coacción ha cambiado el tipo semántico del nombre pero no su tipo sintáctico, por lo que los nombres recategorizados en (20) se comportan como individuales respecto de las pruebas ilustradas en (17-19).

\subsection{Un análisis subléxico de la recategorización de nombres individuales en colectivos}

La interpretación colectiva que los nombres 'banco', 'colegio', 'periódico' y 'trabajo' exhiben en (20) se obtiene de manera indirecta, a través de un mecanismo de coacción por el cual un nombre de [institución/entidad] se recategoriza como [conjunto de miembros]; la recategorización se produce porque existe una predisposición léxica y porque la palabra entra en un determinado contexto. La predisposición léxica se refiere a la existencia de un rasgo sub-léxico en la EQ de los nombres susceptible de explotación por un predicado, que constituye el contexto de la recategorización.

En (21) se recoge una propuesta de EQ para 'banco', 'colegio' y 'periódico': 
(21) EQ: 'banco', 'colegio' y 'periódico'

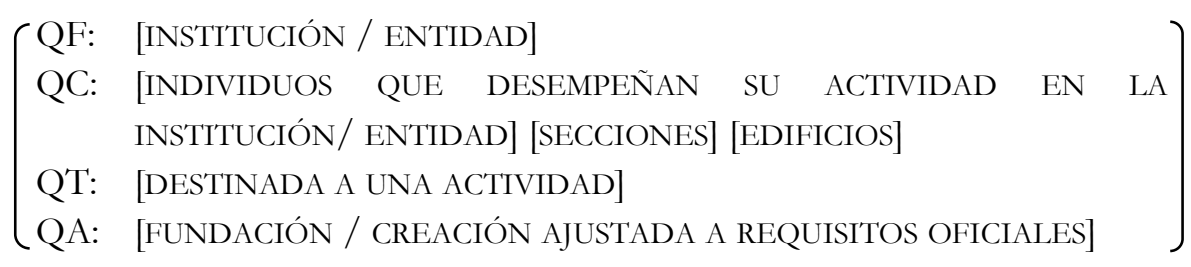

Según (21), una institución o entidad es un objeto artificial creado para desarrollar una actividad. El nombre de tipo funcional que la designa contiene información, hipotéticamente codificada en su EQ, sobre una pluralidad de individuos que conforman la institución o entidad y desarrollan su actividad típica. La combinación con los verbos 'entrar' y 'salir' fuerza una interpretación por la cual el sujeto pasa a formar parte de la pluralidad de individuos y el nombre 'parece' colectivo.

El análisis parte de los siguientes presupuestos: (a) los verbos 'entrar' y 'salir' predican el paso del sujeto a un [lugar] / [estado] distinto de aquel en que se encuentra: 'entrar \{al bosque / en una depresión\}', 'salir \{del bosque / de la depresión\}'; (b) los nombres 'banco', 'colegio' y 'periódico' codifican en su QF el rasgo [institución / entidad], es decir, no se definen como nombres de [lugar] ni de [estado]; (c) en principio, 'entrar' y 'salir' deben ser incompatibles con 'banco', 'colegio' y 'periódico'.

El hecho de que, en contra de lo previsto, la combinación de 'entrar' y 'salir' con 'banco', 'colegio' y 'periódico' sea aceptable se debe a la actuación de un mecanismo de coacción de tipo, que permite a los verbos acceder al contenido del QC del nombre, que codifica contenido relativo a la pluralidad de individuos que desempeñan su actividad en la [institución / entidad]. Tras la coacción, la expresión resultante predica que el sujeto 'pasa a ser, o deja de ser, uno de los individuos que desempeña la actividad típica de la institución o entidad y, por tanto, pasa a formar parte de ella'. En ese sentido, el individuo que entra (ingresa, se incorpora) en una entidad o institución, o sale de ella (la abandona), 'pasa a estar en un estado nuevo' o 'deja de estar en un estado previo'.

El análisis propuesto explica que los nombres 'banco', 'colegio' y 'periódico', aunque no son colectivos, designen un grupo de manera indirecta, cuando son coaccionados por los verbos 'entrar' y 'salir', que explotan una información codificada en una parte de su entrada léxica. Ahora bien, el contenido explotado mediante coacción no está codificado en el QF del nombre, sino que se recupera del QC de la definición del nombre, y no es, por tanto, accesible al conjunto de pruebas que establecen la categorización de un nombre como colectivo. La recategorización de 
'banco', 'colegio' y 'periódico' supone un cambio de clase léxica transitorio y no estable.

Por otra parte, como acaba de mencionarse, 'entrar' y 'salir' son verbos de movimiento y seleccionan como complemento nombres con el rasgo sub-léxico [lugar], como 'pinar' o 'pueblo'; combinados con ellos denotan el evento de '\{pasar a estar / dejar de estar\} en el lugar denominado \{'pinar'/'pueblo'\}', como en (14k). Pues bien, dado que los nombres de institución y entidad se refieren a objetos con una sede física, constan de dos rasgos en su QF; son nombres de tipo complejo, que se definen como [institución / entidad] - [lugar], y pueden materializar cada rasgo de forma distributiva: en predicaciones de cambio de estado (desencadenado por el inicio o el fin de una actividad prototípica), y en predicaciones de cambio de ubicación, como ilustran los pares de ejemplos de (22a-c):

(22) a. Juan entró en el banco \{antes de acabar la carrera / cuando empezó a llover\}.

b. Juan salió del colegio \{a una edad temprana / por la ventana\}.

c. Juan entró en el periódico \{con un contrato temporal / dando un portazo\}.

La predicación de cambio de lugar implica una selección del argumento por parte del predicado; la de cambio de estado implica una coacción del tipo del argumento, de individual a colectivo, puesto que la única manera en que se puede 'entrar' y 'salir' en una institución o entidad es si esta pasa a referirse a la pluralidad de [individuos que desempeña su actividad en la institución / entidad]).

Aparte de los nombres de [institución/entidad], existen otros falsos colectivos: p. ej., 'trabajo', nombre especificado en su QF como [evento]:

(23) Juan salió del trabajo \{por su exceso de celo / porque su móvil no tenía cobertura\}.

Según se ve en (23), 'trabajo' puede nuclear el complemento de 'salir' en los dos sentidos analizados: (a) como parte de la predicación 'dejar de ser parte de la pluralidad de individuos que participan en el trabajo', información presumiblemente codificada en su QA; y (b) como evento de movimiento, en la medida en que 'trabajo' es un evento que se lleva a cabo típicamente en un recinto. En el primer caso, 'trabajo' se recategoriza como colectivo; en el segundo es coaccionado para denotar [lugar], información hipotéticamente codificada también en el QA del nombre, puesto que los eventos se dan en ciertas coordinadas espacio-temporales.

También se recategorizan como colectivos los nombres de [lugar] 'pueblo' y 'ciudad'. De hecho, son nombres de tipo complejo [lugar] • [contenedor]. En la lectura de [lugar], son compatibles con los requisitos léxicos de 'asfaltar', como se ve en (24a); en el sentido de [contenedor], admiten la explotación del rasgo [contenido] codificado en el QT de su EQ: ‘pueblo’ y ‘ciudad' designan contenedores destinados a 
[contener habitantes]. En (24b), 'saludar' explota ese rasgo y 'pueblo/ciudad' se reinterpretan como 'conjuntos de habitantes'. La preposición 'a' ante 'el pueblo / la ciudad', propia de los complementos directos animados, confirma la recategorización del nombre como colectivo y animado.

(24) a. El alcalde ha asfaltado \{el pueblo / la ciudad\}, a pesar de que la oposición estaba en contra.

b. El alcalde ha saludado \{al pueblo/a la ciudad\} desde el balcón del Ayuntamiento, a pesar de que la oposición estaba en contra.

c. Aunque vive allí hace poco, Alicia ya se conoce todo el pueblo.

d. Alicia se conoce a todo el pueblo desde que es directora del banco.

Idéntico contraste ilustran (24c-d): en (24c), 'pueblo' es un nombre individual de lugar no animado y 'todo el pueblo' se refiere a 'la totalidad de una división territorial o administrativa'. En (24d), 'pueblo' se ha reinterpretado como colectivo y se refiere a las personas que habitan en el pueblo; la presencia de la 'a' delante de 'todo el pueblo' indica que el referente en este caso es animado: 'todas las personas que viven en el pueblo'.

En suma, el análisis aquí defendido atribuye la lectura colectiva de algunos nombres individuales de [institución/entidad] ('banco', 'colegio', 'periódico'), de [evento] ('trabajo') y de [lugar] ('ciudad, pueblo') a la intervención de un mecanismo de coacción, que explota un rasgo contenido en su EQ (bien en el QC, bien en el QA, bien en el QT). La recategorización está ligada al contexto en que un predicado coacciona un argumento para cambiar su tipo semántico; fuera de ese contexto, el nombre sigue siendo individual, por lo que responde como tal a las pruebas: rechaza, pues, la combinación con 'numeroso' y 'reducido' con el significado de "compuesto de numerosos o escasos miembros” y la combinación con 'recortar' y 'ampliar' con el significado de "disminución y aumento del número de miembros", entre otras pruebas. En cambio, la combinación con 'salir' y 'entrar' no permite discriminar nombres originariamente colectivos de nombres interpretados esporádicamente como colectivos, como 'banco', 'colegio', 'periódico' o 'trabajo'.

El análisis sub-léxico propuesto tiene interesantes consecuencias en un sentido metateórico, en la medida en que confirma el interés de los presupuestos asumidos: la condición infraespecificada y muy estructurada de las entradas léxicas, la existencia de distintos tipos de palabras en función de la EQ, y la propuesta de mecanismos que operan sobre las palabras para generar nuevos significados. Así, parece que puede afirmarse que en los nombres de entidad o institución, de evento y de lugar que se reinterpretan como colectivos se produce una herencia hacia el QF de la información codificada en otro rasgo de la EQ (el QC, el QA o el QT), que acaba recategorizándolo como [conjunto]. 
Este proceso de herencia de la información se produce también, en sentido inverso, en algunos nombres colectivos: en casos como 'un equipo de baloncesto de médicos' o 'un coro de personal de la universidad', en los que no coinciden los rasgos de la EQ ([QF: baloncestistas] / QC: [médicos]; [QF: cantantes] / QC: [personal de la universidad]), el rasgo relativo al grupo se impone sobre la información acerca de los miembros. Un 'equipo de baloncesto formado por médicos' es un 'colectivo de baloncestistas'. Es decir, en un nombre colectivo el QF define la condición de los miembros: así, 'un equipo de salvamento' está formado por 'personas que van a salvar', con independencia de que sean especialistas en salvamento o ciudadanos reunidos para la ocasión. Por otra parte, la disociación entre QF y QC puede desencadenar un proceso de recategorización inverso al aquí estudiado: el de los nombres colectivos que pasan a designar entidades, y adquieren una EQ diferente, como 'ejército' (ver apartado 4.1. para los nombres complejos con lecturas de conjunto y de entidad).

Estos fenómenos se observan solo en los nombres colectivos de tipo funcional; el QF de los nombres colectivos de tipo natural, como 'rebaño' o 'público', conjuntos cuya existencia no puede darse independientemente de la de sus miembros, contiene información redundante con la codificada en el QC: por tanto, no cabe la posibilidad de que la información del grupo se imponga sobre la de los miembros (como en 'equipo de baloncesto de médicos') ni de que el conjunto de miembros se reinterprete como una entidad (como en 'los aviones del ejército protagonizaron una exhibición aérea'), hecho que avala también la distinción entre nombres de tipo natural y funcional propuesta por el LG (ver sección 3.2.).

\section{CONCLUSIONES}

En las páginas precedentes se ha reflexionado brevemente sobre el concepto de clase léxica y se ha defendido una concepción del léxico dinámica y permeable al contexto que permite dar cuenta de las frecuentes recategorizaciones que experimentan las palabras en determinadas condiciones contextuales. En concreto, el trabajo se ha centrado en la recategorización léxica de algunos nombres individuales, que se reinterpretan como colectivos, en virtud de un rasgo sub-léxico que favorece la operación de un mecanismo de coacción del tipo de nombre denotado. Entre los rasgos sub-léxicos que favorecen la recategorización como colectivo hemos identificado el de [institución / entidad destinada a una actividad, que permite la coacción del nombre para pasar a designar la pluralidad de [individuos que desempeñan una actividad en la institución/entidad] y también el de [evento] y el de [contenedor (de habitantes)]. El análisis de los nombres recategorizados revela que a) sin la presencia del rasgo sub-léxico pertinente, un nombre individual no se puede coaccionar como colectivo: 'pinar' o 'arroz' carecen de rasgos que les permitan denotar conjuntos, por mucho que en el mundo sus referentes puedan percibirse como tales; b) que los rasgos propuestos son de naturaleza lingüística y no ontológica; 
c) que el contexto es fundamental, como desencadenante del mecanismo de coacción: el QC del nombre 'banco' con la lectura de [institución / entidad] se explota en combinación con 'salir' y 'entrar', no en cualquier otro contexto; d) que el nombre recategorizado solo lo está en el contexto de la coacción; en cualquier otro contexto se comporta como un nombre individual, puesto que no designa inicialmente un conjunto de miembros.

En suma, las fronteras entre pertenecer léxica y gramaticalmente a una clase o formar parte contextualmente de ella son más nítidas y regulares de lo que un estudio clásico de la metonimia y otras extensiones figuradas del significado podría hacer creer.

\section{REFERENCIAS BIBLIOGRÁFICAS}

Bosque, I. (1989). Las categorías gramaticales. Madrid: Síntesis.

Bosque, I. (2000). Objetos que esconden acciones. Una reflexión sobre la sincategorematicidad. En T. Cabré \& C. Gelpí (Eds.), Lexic, Corpus i Diccionaris. Cicle de conferencies i seminaris '97-'98 (pp.15-31). Barcelona: IULA.

Bosque, I. (Dir.) (2004). REDES. Diccionario combinatorio del español contemporáneo. Madrid: SM.

Bosque, I. (2016). Sustantivo. En J. Gutiérrez-Rexach (Dir.), Enciclopedia de Lingüística Hispánica (pp. 111-123). Londres/Nueva York: Routledge.

Cabezas, E. (2017). Las expresiones colectivas en español. Madrid: Arco/Libros.

Copestake, A. (1995). The representation of group denoting nouns in a lexical knowledge base. En P. Saint-Dizier \& E. Viegas (Eds.), Computational lexical semantics (pp. 217-230). Cambridge: Cambridge University Press.

De Miguel, E. (2003). Sobre la silepsis: Un análisis léxico-semántico de la discordancia inducida por mitad. Revista de Investigación Lingüistica, VI(1), 143-173.

De Miguel, E. (2009). La teoría del lexicón generativo. En E. De Miguel (Ed.), Panorama de la lexicología (pp. 336-368). Barcelona: Ariel.

De Miguel, E. (2011). En qué consiste ser verbo de apoyo. En V. Escandell, M. Leonetti \& C. Sánchez (Eds.), 60 Problemas de Gramática (pp. 139-146). Madrid: Akal.

De Miguel, E. (2014). La lexicología en España. Tendencias y proyectos en curso. En R. García Pérez (Dir.), La lexicologie en Espagne: De la lexicologie à la lexicographie. Número monográfico de Cabiers de Lexicologie, 104(1), 17-44. 
De Miguel. E. (2015). Lexical agreement processes: On the construction of verbal aspect. En J. L. Cifuentes Honrubia, E. Barrajón \& S. Rodríguez Rosique (Eds.), Verbal classes and aspect (pp. 131-152). Ámsterdam: John Benjamins.

De Miguel, E. (2016). Lexicología. En J. Gutiérrez-Rexach (Dir.), Enciclopedia de Lingüistica Hispánica (pp. 173-185). Londres/Nueva York: Routledge.

De Miguel, E. \& Fernández Lagunilla, M. (2000). El operador aspectual SE. RSEL, 30(1), 13-43.

De Miguel, E. \& Batiukova, O. (2017). Compositional mechanisms in a generative model of the lexicón. En S. Torner \& E. Bernal (Eds.), Collocations and Other Lexical Combinations in Spanish. Theoretical, lexicographical and applied perspectives (pp. 92-113). Londres/Nueva York: Routledge.

Marín, R. (2004). Entre 'ser' y 'estar'. Madrid: Arco/Libros.

Marín, R. (2015) (Ed.). Los predicados lexicológicos. Madrid: Visor.

Pustejovsky, J. (1995). The Generative Lexicon. Cambridge, Mass: MIT Press.

Pustejovsky. J. (2011). Coercion in a General Theory of Argument Selection. Linguistics, 49(6), 1401-1431.

Pustejovsky, J. \& Batiukova, O. (2018). Lexicon. Cambridge: Cambridge University Press.

Pustejovsky, J. \& Ježek, E. (2008). Semantic Coercion in Language: Beyond Distributional Analysis. Rivista di Linguistica, 20(1), 182-214.

Romero, J. (2017). Subcategorías nominales en español: Comportamiento léxicosintáctico y mecanismos coercitivos. Cuadernos CANELA, 28, 160-178.

RAE/ASALE (2017). Diccionario de la lengua española. Versión electrónica 23.1 [en línea]. Disponible en http://dle.rae.es/

\section{NOTAS}

1 La investigación que subyace al presente trabajo ha sido parcialmente financiada por el proyecto de investigación Diccionario Reticular del Español. Diccionario analógico y relacional con acceso en red desde el sentido y desde la forma (FFI2017-83293), subvencionado por el Ministerio de Economía, Industria y Competitividad del Gobierno de España. Quiero expresar mi agradecimiento a Pedro Álvarez de Miranda, a Olga Batiukova y a Jorge Agulló por la ayuda prestada en diversas fases de la investigación. 
${ }^{2}$ En la medida en que un grupo de entidades comparten una parte de su definición que las legitima como miembros de un conjunto, su estatus como miembros es idéntico. Todo miembro de 'rebaño' es 'oveja' y todo miembro de 'público' es 'espectador'. Cuando una agrupación reúne miembros de distinto estatus no constituye, por definición, un colectivo sino un grupo de otra naturaleza, p.ej., una entidad o institución: así, 'ejército', según recoge el Diccionario de la Lengua Española de la RAE/ASALE (2017; a partir de ahora, DLE) tiene una acepción como colectivo y otra como entidad o institución. Lo mismo puede proponerse para 'club' y 'departamento'. Copestake (1995) y Cabezas (2017), en cambio, defiende que los nombres colectivos pueden referirse a grupos con miembros de distinta naturaleza.

${ }^{3}$ La gama de colectivos en función de sus miembros es relativamente variada. Cabezas (2017) ofrece una clasificación muy exhaustiva, aunque basada en parámetros menos restrictivos que los aquí manejados.

4 No nos interesa aquí la acepción de 'banco' y 'colegio' cuyo QC codifica [PECES] y [PROFESIONALES COLEGIADOS] respectivamente; en ese caso, su comportamiento es el esperado para los nombres colectivos.

${ }^{5}$ La compatibilidad con un SP que visualice el contenido del QC de un nombre es una condición necesaria para definirlo como colectivo pero no suficiente: algunos nombres no colectivos pueden coaparecer con un SP que materializa partes o elementos de su estructura interna: 'una bicicleta de ruedas anchas'; 'una cordillera de montes o peñascos cortados'; 'un arroz de granos alargados, más delgados y planos’ (https://restaurantecasaangel.com/noticias/ saber-mas-sobre-el-arroz-y-sus-diferentes-variedades/).

${ }^{6}$ Los nombres que, según el buscador Google, aparecen más a menudo como complemento de 'formar' son: 'familia', 'asociación', 'cooperativa', 'equipo', 'partido (político)' y 'sindicato', todos ellos colectivos, aunque también se encuentran ejemplos con nombres de otras clases léxicas ('formar un hogar', 'formar un juicio'). La compatibilidad con 'formar' se trata, pues, de una condición necesaria pero no suficiente: si el nombre es colectivo, la satisface (por tanto, 'gente' y 'arroz' no lo son) pero no por satisfacerla es forzosamente colectivo, como ocurre con la prueba de la materialización de las partes de un SP (ver Nota 4).

${ }^{7}$ Existe un interesante contraste entre '(se) salió del grupo' y '(*se) salió del pueblo', que avala el carácter no colectivo de 'pueblo'. El predicado ‘salir del grupo' denota un evento que acaba y da paso a un estado nuevo ('no ser parte del grupo'): admite, pues, el 'se aspectual' (para su contenido y propiedades, De Miguel \& Fernández Lagunilla, 2000). 'Salir del pueblo' describe un evento puntual de movimiento, el paso de un lugar (el pueblo) a otro diferente, que no focaliza el estado subsiguiente ('pasar a estar en otro sitio' $\neq$ 'dejar de ser del pueblo'), por lo que está vedada la aparición del 'se aspectual' (De Miguel, 2009 para otros contrastes similares entre 'salir' y la variante con clítico 'salirse').

${ }^{8}$ En (15c), el pronombre 'les' de 'enviarles' no solo concuerda en plural, sino que aparece en dativo: supone un caso de 'leísmo de persona' típico del español europeo, pero el nombre ‘equipo' no es un nombre de persona. La concordancia 'canónica' impondría el singular y el 
acusativo ('enviarlo'). El ejemplo muestra que la sintaxis accede al rasgo [MIEMBROS DEL CONJUNTO] que los nombres colectivos codifican en su QC.

${ }^{9}$ Según Copestake (1995), cuyos ejemplos reproduzco y traduzco, las condiciones en que los colectivos concuerdan en plural con el verbo en inglés son menos restrictivas ('That band has/have been playing well' 'esa banda \{ha/han\} estado tocando bien'); con todo, la doble concordancia está ligada a la interpretación colectiva o distributiva del nombre, como la de los partitivos en español, aunque el comportamiento no es idéntico. En inglés, en singular solo se procesa la lectura colectiva ('the committee gets £20.000 ('each)' 'el comité recibe 20000 £ al año (cada uno)') mientras que el plural permite tanto la colectiva como la distributiva ('the committee get $£ 20.000$ per annum (each)' 'el comité en conjunto recibe $20000 £$ al año'/ 'cada miembro del comité recibe $20000 £$ al año'). Con los partitivos en español, la concordancia plural solo permite la lectura colectiva ('la mitad de los plátanos están marrones' $\approx$ 'la mitad del conjunto de los plátanos está marrón') mientras que en singular se legitiman ambas lecturas: 'la mitad de los plátanos está marrón’ $\approx$ ‘\{la mitad del conjunto / la mitad de cada plátano $\}$ está marrón'; De Miguel, 2003). En suma, en ambas lenguas el plural se puede ligar a la lectura colectiva, lo que indica que la sintaxis puede acceder a la información contenida en el interior de la EQ del nombre colectivo, que en su QF está especificado como singular y en su QC incluye información sobre los elementos que componen una multiplicidad.

${ }^{10}$ La cuestión de si los colectivos son siempre contables o no está pendiente de investigación. Para algunos autores existen colectivos no contables (Cabezas, 2017). Las pruebas aquí recogidas sugieren, más bien, que los colectivos son contables, aunque se pueden recategorizar como no contables, cuando adquieren un nuevo sentido, de entidad o institución: por ejemplo, 'familia' es un nombre de tipo natural, que alude a una relación de parentesco ('forma parte de una familia numerosa') pero también un nombre de tipo funcional que se refiere a una entidad artificial (legal, social...: 'ha legado su fortuna a una ONG porque no tiene (mucha) familia'): el nombre de tipo natural es un colectivo contable (como 'colegio' en 'forma parte de un colegio de abogados'); el nombre de tipo funcional es individual no contable (como 'colegio' en 'aún no tiene colegio en su nueva ciudad, esperamos que pronto pueda ir a clase'). Hay algún ejemplo que se resiste a este análisis: 'clero' parece un nombre colectivo no contable ('en la alta Edad Media había mucho clero, un clero numeroso e improductivo'); tal vez el estatus de colectivo proceda, en este caso, de una recategorización desde una lectura original de clase o institución, explicación que también podría darse para 'aristocracia'. En todo caso, esta cuestión no afecta a la validez de la prueba propuesta respecto de la compatibilidad de 'entre' con los nombres colectivos.

${ }^{11}$ En cuanto a la coaparición con un SP que visualice un subconjunto de los miembros de un grupo, como vimos (Nota 4), es una condición que un nombre colectivo debe satisfacer pero que también cumplen algunos nombres individuales: los que codifican en su QC información sobre partes, piezas o componentes ('una bicicleta de tres ruedas', 'un arroz de granos alargados'). Puede darse, pues, con nombres de entidad como 'banco', pero su interpretación confirma que no es colectivo: \# 'un banco de empleados jóvenes' es 'una entidad en la que trabajan personas jóvenes', no 'un conjunto cuyos miembros son personas jóvenes'. 